http://dx.doi.org/10.23925/1983-3156.2021v23i1p140-170

\title{
Em busca de compreensões sobre os objetos de aprendizagem na educação matemática por meio de uma revisão sistemática de literatura \\ In search of understanding about learning objects in mathematics education through a systematic literature review
}

\section{En busca de la comprensión sobre los objetos de aprendizaje en la educación matemática a través de una revisión sistemática de la literatura}

\author{
Marcelo Souza Motta ${ }^{1}$ \\ Universidade Tecnológica Federal do Paraná \\ https://orcid.org/0000-0001-5534-2735 \\ Marco Aurélio Kalinke ${ }^{2}$ \\ Universidade Tecnológica Federal do Paraná \\ https://orcid.org/0000-0002-5484-1724
}

\begin{abstract}
Resumo
A proposta deste artigo é apresentar um panorama das dissertações, realizadas nos programas stricto sensu brasileiros que versam sobre a utilização de objetos de aprendizagem na educação matemática. A pesquisa é qualitativa e utiliza como procedimento inventariante uma revisão sistemática de literatura (RSL). O cenário da pesquisa foi constituído pelos trabalhos disponibilizados no Catálogo de Teses e Dissertações da Capes no período de 2013 a 2018. A busca inicial ocorreu no mês de maio de 2020 e, após a aplicação dos protocolos de pesquisa, resultou na identificação de 25 dissertações, que foram organizadas, por meio da leitura flutuante de seus títulos, resumos, palavras-chaves ou capítulos. Os resultados apontam a relevância das pesquisas, destacando as contribuições dos objetos de aprendizagem (AO) nos processos de ensino e aprendizagem e demonstram a possibilidade de construção dos próprios artefatos digitais pelos professores, adequando-os aos seus contextos pedagógicos específicos. Apesar disso, notamos a baixa realização de pesquisas dessa temática, em detrimento de outras

\footnotetext{
${ }^{1}$ marcelomotta@utfpr.edu.br

2 kalinke@utfpr.edu.br
} 
relacionadas com o uso das tecnologias na educação matemática e a não existência de uma uniformização dos autores sobre o que se entende por OA. Por fim, destacamos que a metodologia adotada não é rígida, podendo ser remodelada por outros pesquisadores, sendo capaz de apresentar outros portifólios bibliográficos.

Palavras-Chave: Objetos de aprendizagem, Educação matemática, Revisão sistemática de literatura, Tecnologias digitais.

\begin{abstract}
The purpose of this article is to present an overview of the research, carried out in the Brazilian stricto sensu programmes that talk about the use of learning objects in mathematics education. The research is qualitative and uses a systematic literature review (SLR) as the inventory procedure. The research landscape was constituted by the works available in the Catálogo de Teses e Dissertações da Capes/Capes Dissertations and Theses Catalogue from 2013 to 2018. The initial search happened in May 2020 and, after applying the research protocols, we identified 25 thesis, which we organised, through skimming through their titles, abstracts, keywords, or chapters. The results point out the relevance of the research, highlighting OA's contributions to the teaching and learning processes and demonstrating the teachers' possibility of constructing their own digital artefacts, adapting them to their specific pedagogical contexts. Despite this, we noticed there were few studies on this topic, to the detriment of others about the use of technologies in mathematics education and the lack of authors' consistency on what is meant by OA. Finally, we emphasise that the methodology adopted is not rigid. It can be remodelled by other researchers and present other bibliographic portfolios.
\end{abstract}

Keywords: Learning Objects, Mathematical Education, Systematic Literature Review, Digital Technologies 


\section{Resumen}

El propósito de este artículo es presentar una visión general de las disertaciones, realizadas en los programas stricto sensu brasileños que se ocupan del uso de objetos de aprendizaje en la educación matemática. La investigación es cualitativa y utiliza una revisión sistemática de la literatura (RSL) como procedimiento de inventario. El escenario de investigación estuvo constituido por los trabajos dispuestos en el Catálogo de Teses e Dissertações da Capes/Catálogo de Tesis y Disertaciones de Capes de 2013 a 2018. La búsqueda inicial se dió en mayo de 2020 y luego de la aplicación de los protocolos de investigación, se identificaron 25 disertaciones, que se organizaron a través de la lectura flotante de sus títulos, resúmenes, palabras clave o capítulos. Los resultados señalan la relevancia de la investigación, destacando las contribuciones de los objetos de aprendizaje (OA) en los procesos de enseñanza y aprendizaje y demuestran la posibilidad de que los profesores construyan sus propios artefactos digitales, adaptándolos a sus contextos pedagógicos específicos. A pesar de esto, observamos el bajo nivel de investigación sobre este tema, en detrimento de otros relacionados con el uso de tecnologías en la educación matemática y la falta de uniformidad de los autores sobre lo que se entiende por OA. Finalmente, enfatizamos que la metodología adoptada no es rígida, puede ser remodelada por otros investigadores y presentar otras carteras bibliográficas.

Palabras clave: Objetos de aprendizaje, Educación matemática, Revisión sistemática de literatura, Tecnologías digitales. 


\section{Em busca de compreensões sobre os objetos de aprendizagem na educação matemática por meio de uma revisão sistemática de literatura}

Na sociedade atual, permeada por artefatos tecnológicos, os processos educacionais estão sujeitos aos impactos causados pelas transformações e inovações tecnológicas constantemente inseridas no contexto escolar. Cabe às escolas desenvolver novas metodologias que incorporem as tecnologias digitais (TD) em suas atividades educacionais, bem como oferecer novas propostas pedagógicas para inseri-las nestas atividades.

Ainda que as TD possam ser inseridas nos processos educacionais com justificativas sociológicas, tais como o fato da escola ser uma oportunidade ímpar para incluir alunos em risco social no mundo tecnológico, ou que a sociedade contemporânea exija o domínio das TD nas mais variadas profissões, estas não podem ser as únicas justificativas. Entendemos ser necessária uma fundamentação teórica consistente, do ponto de vista das mudanças educacionais, que essa inserção pode trazer aos processos de ensino e de aprendizagem.

Neste viés, encontramos suporte nas ideias de quatro autores que se complementam e que têm sido usados nos nossos grupos de pesquisas como referência para os trabalhos que desenvolvemos, relacionados à inserção de TD em aulas de Matemática. São eles, Lévy (1993), Tikhomirov (1981), Kenski (2007) e Borba \& Vilarreal (2005).

Lévy (1993) nos oferece uma visão do impacto das tecnologias nas sociedades, indicando que estas modificam as formas de produzir e transmitir conhecimentos em função das tecnologias que estão à disposição dos coletivos sociais. Tikhomirov (1981) faz uma análise similar à de Lévy, mas enquanto aquele direciona seus estudos às sociedades, este direciona seu foco para os indivíduos, e nos apresenta a ideia de que eles têm sua capacidade criativa reorganizada quando usam novas tecnologias. Kenski (2007) defende a inserção das tecnologias no ambiente escolar suportadas por uma nova pedagogia, que permita explorá-las de forma diferenciada, e Borba \& Vilarreal (2005), por sua vez, nos apresentam a ideia do 
“seres-humanos-com-mídias...", segundo a qual modificamos nossa forma de fazer Matemática de acordo com as tecnologias que temos à disposição.

Estas referências teóricas nos dão condições de defender, do ponto de vista pedagógico, a inserção das TD em aulas de Matemática. É neste viés, e com esta fundamentação, que nos dedicamos a estudá-las e compreendê-las. Entre os diversos recursos e possibilidades que temos à disposição, direcionamos um olhar especial para os Objetos de Aprendizagem (OA). Nesta perspectiva, este artigo tem como objetivo identificar as pesquisas, no catálogo de teses e dissertações da Capes, que discorrem sobre objetos de aprendizagem na Educação Matemática.

\section{Os Objetos de Aprendizagem}

Os OA começaram a ser estudados no início deste milênio, e têm em Wiley (2000) um dos seus pioneiros. Para este autor, eles podem ser entendidos como sendo

Pequenos componentes instrucionais (em relação ao tamanho de um curso inteiro) que podem ser reutilizados várias vezes em diferentes contextos de aprendizagem. Além disso, os objetos de aprendizagem são geralmente entendidos como entidades digitais que podem ser entregues pela Internet, o que significa que qualquer número de pessoas pode acessá-los e usá-los simultaneamente (Wiley, 2000, p. 3).

Em busca de novas compreensões, diversos autores têm se dedicado a apresentar suas definições ou características dos OA. Entre eles destacamos Tavares (2008; 2010), Mendes, Souza \& Caregnato (2007) e Gutierres (2004). As definições apresentadas, contudo, nem sempre atendem ao que pesquisadores e grupos de pesquisa entendem por OA. Os autores deste trabalho usam, por exemplo, as definições do Grupo de Pesquisa em Inovação e Tecnologias na Educação (GPINTEDUC) e do Grupo de Pesquisas sobre Tecnologias na Educação Matemática (GPTEM).

Para o GPINTEDUC, os OA podem ser definidos como "recursos digitais para suporte à aprendizagem de um conteúdo específico, por meio da interatividade, que podem ser usados 
e reutilizados, em diferentes níveis e modalidades de ensino 3 "”. O GPTEM, por sua vez, os considera como sendo "quaisquer recursos virtuais multimídia, que podem ser usados e reutilizados com o intuito de dar suporte a aprendizagem de um conteúdo específico, por meio de atividade interativa, apresentada na forma de animação ou simulação ${ }^{4}$. Estas duas definições guardam entre si a similaridade de compreensão sobre os OA quanto a serem recursos tecnológicos, interativos, relativos a conteúdos específicos e que possam ser usados e reutilizados. É assim que eles serão aqui compreendidos.

Diversos outros autores têm analisado o potencial pedagógico da inserção dos OA em aulas de Matemática (Schmitt, Corbellini, 2014; Pinto, Laudares, 2016; Elias, Motta, Kalinke, 2018; Motta, Kalinke, Curci, 2019). Para Kalinke \& Motta (2018, p. 11) "há uma clara indicação de que os OA podem agregar possibilidades inovadoras ao ensino da Matemática" e ainda que a "utilização dos OA tem potencial para mudar a dinâmica das aulas, incorporando novas possibilidades de trabalho pedagógico, que façam uso de exploração, simulação e interação, com atividades nas quais a busca pelo conhecimento seja uma constante" (Kalinke \& Motta, 2018, p. 11).

Estudos sobre os OA vêm sendo desenvolvidos no Brasil desde o início dos anos 2000. No ano de 2007 o Ministério da Educação publicou um livro com a intenção de divulgar o uso dos OA como recursos pedagógicos (BRASIL, 2007). Desde então, pesquisas têm sido realizadas em busca de aumentar a compreensão sobre o uso, criação e possibilidades pedagógicas relativas aos OA. No GPTEM e GPINTEDUC temos direcionados esforços para a construção de OA com base em aplicativos e plataformas disponíveis gratuitamente na web, tais como o Scratch, o App Inventor 2, e o Hot Potatoes, entre outros. Também temos explorado

\footnotetext{
${ }^{3}$ https://gpinteduc.wixsite.com/utfpr/definicoes-do-grupo

${ }^{4}$ https://gptem5.wixsite.com/gptem/sobre-1
} 
as possibilidades de construí-los usando ferramentas do Microsoft Excel e Power Point, por exemplo. Ainda que os resultados sejam animadores, é importante observar que

A elaboração e difusão dos OA nos repositórios não bastam para repercutir mudanças na sala de aula. Faz-se necessário uma efetiva formação docente, centrada no uso de $\mathrm{OA}$, com a finalidade de introduzi-los na sua prática docente. A prática escolar precisa acompanhar as mudanças da sociedade e dos novos alunos, adequando-se a novas metodologias, por exemplo (Kalinke \& Motta, 2018, p. 15).

O exposto até aqui nos leva à necessidade de aprofundar as pesquisas sobre o assunto e, para tanto, entendemos ser necessário realizar uma revisão de literatura do que já existe de estudos realizados, para que se possa, a partir dela, propor novas pesquisas em busca de compreensões maiores e mais gerais sobre a temática.

\section{A metodologia da pesquisa}

O presente estudo consiste em uma pesquisa de abordagem qualitativa, que utiliza como procedimento uma pesquisa bibliográfica, por meio de uma Revisão Sistemática de Literatura (RSL). Para Galvão \& Pereira (2014, p. 183) uma RSL é “[...] um tipo de investigação focada em questão bem definida, que visa identificar, selecionar, avaliar e sintetizar as evidências relevantes disponíveis [...]" de um certo estudo ou temática de interesse. As pesquisas de RSL são consideradas estudos secundários, pois surgem a partir de estudos primários existentes em um campo ou área de conhecimento.

As RSL, da mesma forma que outros estudos inventariantes, são importantes fontes de informações sobre determinada temática, área de concentração ou linha de pesquisa, pois, disponibilizam uma síntese "[...] das evidências relacionadas a uma estratégia de intervenção específica, mediante a aplicação de métodos explícitos e sistematizados [...]” (Sampaio \& Mancini, 2007, p. 84). Segundo Fiorentini et al (2016) pesquisas do tipo inventariante, permitem identificar informações sobre os estudos em um prazo de tempo delimitado, apresentando informações físicas dessa produção, tais como, “onde, quando e quantos estudos foram produzidos ao longo do período e quem foram os autores e participantes dessa produção" 
(Fiorentini et al, 2016, p. 18). A RSL, “preocupa-se mais com a caracterização dos estudos do que com a realização de conjecturas e análises sobre as informações investigadas” (Motta, Basso \& Kalinke, 2019, p. 206).

As pesquisas do tipo RSL são muito utilizadas na Ciência da Saúde, pois, possibilitam caracterizar informações de um grupo ou população específica, propiciando a avaliação dos impactos da temática e a promoção de ações futuras a serem implementadas pela área. Em específico, nas áreas de Educação e Ensino, a RSL permite categorizar as informações, identificando aspectos teóricos, metodológicos, lacunas, semelhanças e diferenças entre os estudos, permitindo (re)articular os saberes existentes sobre a temática, oportunizando trilhar novos caminhos do que se busca conhecer.

Figura 1.

Fases da RSL definidas nesta pesquisa. (Autoria Própria, 2020).

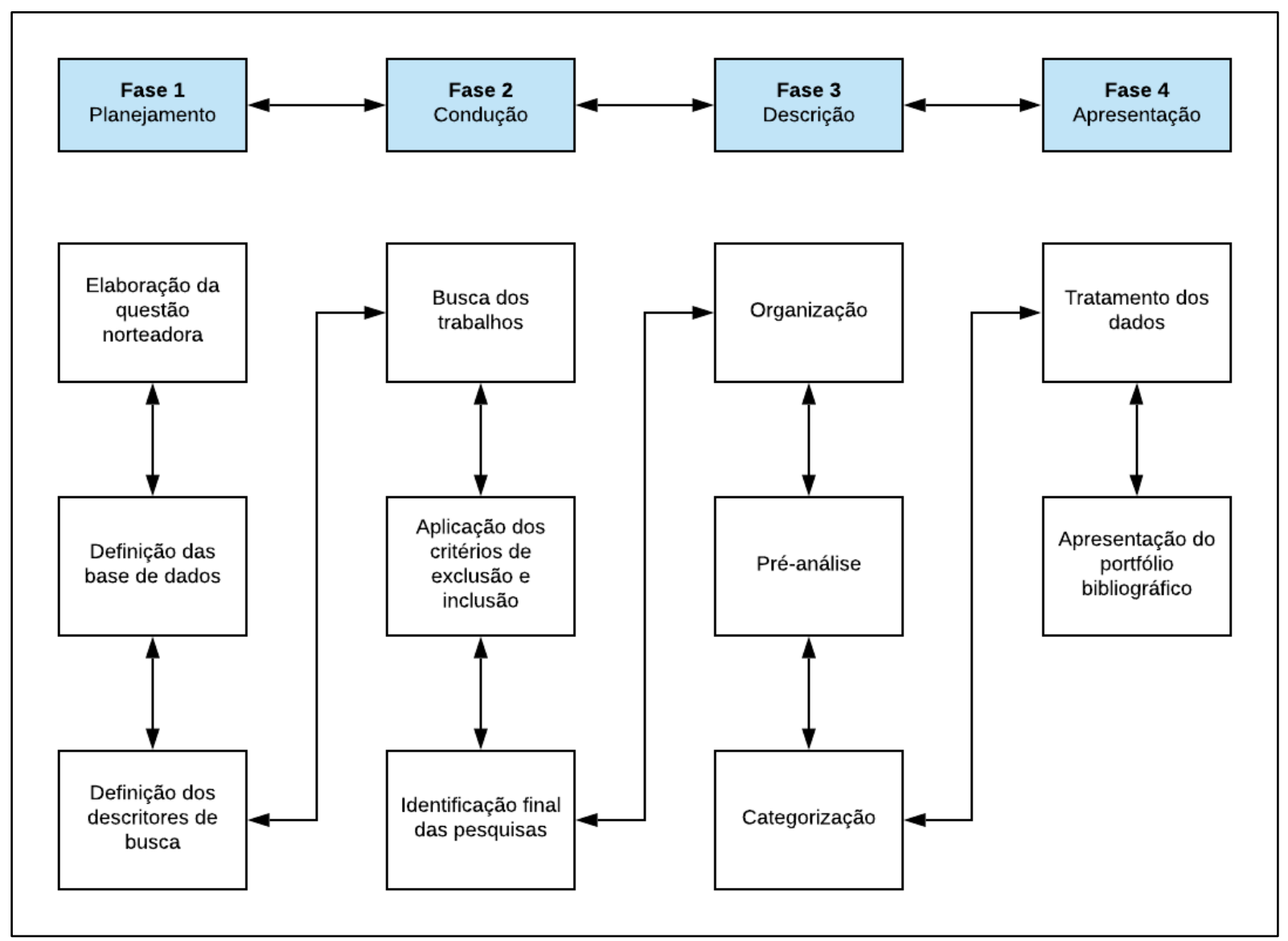

Para esse estudo organizamos a RSL em quatro fases que são: planejamento, condução, descrição e apresentação, conforme apresentado na Figura 1. Estas fases não são desconexas, 
podendo ser retomadas e retroalimentas em qualquer momento do processo de revisão. A fase do planejamento estabelece a necessidade de realização do estudo por meio de uma questão norteadora, que conduz todo o protocolo da pesquisa, e nela também são definidos o(s) banco(s) de dado(s) e os descritores que serão utilizados.

Na fase de condução ocorre a busca pelos trabalhos, são aplicados os critérios de exclusão e inclusão, definidos com base na questão e nas limitações dos estudos, estabelecendo-se a identificação das pesquisas. Na descrição ocorre a organização das pesquisas, a realização de uma pré-análise e a categorização. Por fim, na apresentação dos dados ocorre o tratamento dos dados e a divulgação do portifólio bibliográfico final, estabelecendo conexões e/ou semelhanças entre os estudos. Nos próximos tópicos destacaremos as fases desta RSL.

\section{O planejamento e a condução da revisão sistemática de literatura}

Iniciamos a fase de planejamento destacando a questão norteadora que conduzirá todo o protocolo de pesquisa: Quais as pesquisas no Catálogo de Teses e Dissertações da Capes que discorrem sobre objetos de aprendizagem na Educação Matemática? Definimos o Catálogo de Teses e Dissertações da Capes $^{5}$ como referência para a coleta dos dados, pois, disponibiliza informações sobre as pesquisas desenvolvidas em todos os programas stricto sensu brasileiros. Segundo o painel de informações quantitativas da plataforma, até a condução da RSL, que ocorreu em maio de 2020, estão disponibilizadas mais de 425 mil dissertações, considerando os programas acadêmicos e profissionais, e mais de 144 mil teses. Os descritores para a realização da busca, estabelecidos pelos autores deste artigo, são "objetos de aprendizagem", “objeto de aprendizagem" e "educação matemática".

A busca associou descritores ao operador booleano "and". Inicialmente, a expressão registrada na ferramenta de busca do repositório foi "tecnologia" and "educação matemática".

\footnotetext{
${ }^{5}$ https://catalogodeteses.capes.gov.br/catalogo-teses/\#!/
} 
Foram identificados 902 resultados, que pela quantidade de pesquisas retornadas, dificultaria a realização da RSL. Destarte, decidimos a adoção de outros descritores mais específicos, "objetos de aprendizagem" and "educação matemática" e "objeto de aprendizagem" and “educação matemática". Foram retornados 75 resultados, nos quais foram aplicados os critérios de exclusão e inclusão, conforme protocolo de pesquisa apresentado na Figura 2.

Figura 2.

Protocolo de Condução da RSL (Autoria Própria, 2020).

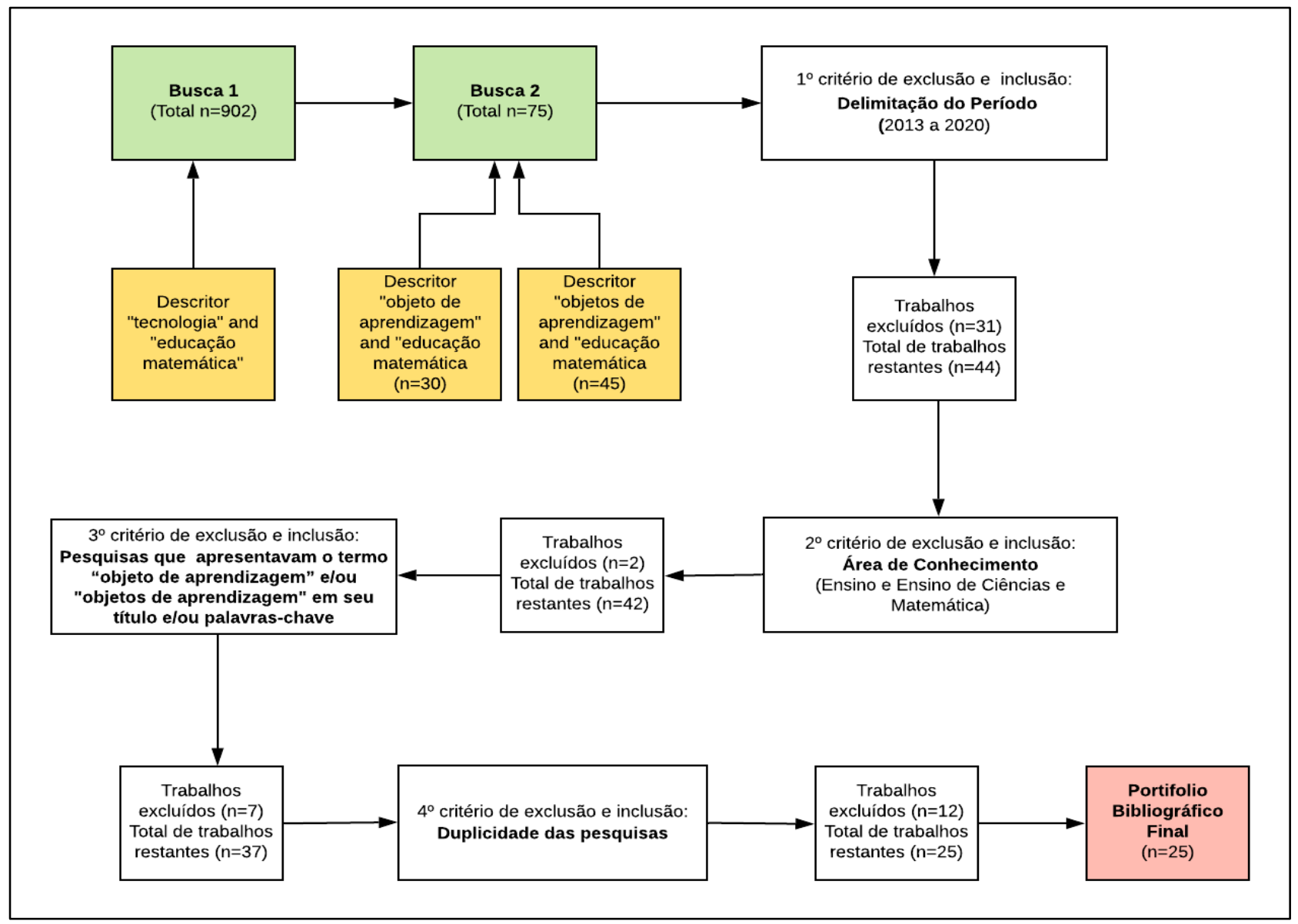

O primeiro critério foi a delimitação do marco temporal, estabelecemos o período de 2013 a 2020. Optamos em excluir os trabalhos realizados antes da implementação da plataforma Sucupira ${ }^{6}$, pois, não apresentavam informações suficientes para a realização desta RSL. O segundo critério foi determinado pela área de conhecimento dos trabalhos, ou seja,

\footnotetext{
${ }^{6}$ A plataforma Sucupira, foi implementada em 2013, e consiste em um repositório para disponibilizar informações sobre as pesquisas realizadas nos programas de pós-graduação stricto sensu no Brasil. Disponível para acesso em https://sucupira.capes.gov.br/sucupira/.
} 
foram incluídos apenas aqueles que se enquadravam nas áreas de Ensino e Ensino de Ciências e Matemática. Convém destacar que não foram identificados estudos na Área de Educação, para o marco temporal estabelecido, por isso essa área não fez parte desta RSL. No terceiro recorte identificou-se no título e/ou palavras-chaves, expressões que indicavam nas pesquisas o uso de objetos de aprendizagem na Educação Matemática. Por fim, o quarto critério definido foi a exclusão das pesquisas que se apresentavam em duplicidade.

Ao final do processo de condução foram selecionados 25 estudos que compõem o base de dados da RSL e perfazem, aproximadamente, 2,8\% do universo das pesquisas que investigam o uso de tecnologias na Educação Matemática.

\section{A descrição dos dados da revisão sistemática de literatura}

$\mathrm{Na}$ descrição as pesquisas identificadas na fase de condução são organizadas, préanalisadas e, se necessário, categorizadas, buscando identificar as principais características e similaridades nos estudos. Inicialmente realizamos a leitura flutuante dos resumos, possibilitando um primeiro contato com os dados coletados, de forma a promover "[...] uma melhor assimilação do material e elaborações mentais que forneceram indícios iniciais no caminho a uma apresentação mais sistematizada dos dados" (Campos, 2004, p. 611). Nessa etapa todos os trabalhos foram fichados "buscando identificar o foco investigativo e pontos de convergências” (Motta, Kalinke \& Mocrosky, 2018, p. 72).

Na Tabela 1 apresentamos as pesquisas identificadas, organizando-as por ano, autor, título e objetivo geral. Para sete dissertações necessitou-se a leitura mais abrangente dos capítulos de introdução e metodologia, pois, não apresentam de forma evidenciada o objetivo geral em seus resumos. 
Tabela 1.

Organização dos dados da RSL (Fonte: Autoria Própria, 2020).

\begin{tabular}{|c|c|c|c|}
\hline Ano & Autor & Título & Objetivo Geral \\
\hline \multirow{3}{*}{2013} & $\begin{array}{l}\text { Nazarreno } \\
\text { Correa }\end{array}$ & $\begin{array}{l}\text { Estudo das pavimentações do plano } \\
\text { utilizando um objeto de aprendizagem. }\end{array}$ & $\begin{array}{l}\text { Identificar a forma como um OA } \\
\text { favorece ao estudo das pavimentações de } \\
\text { um plano formado por polígonos } \\
\text { regulares. }\end{array}$ \\
\hline & $\begin{array}{c}\text { Renata } \\
\text { Ercilia } \\
\text { Mendes } \\
\text { Nifoci }\end{array}$ & $\begin{array}{l}\text { Conhecimentos revelados por } \\
\text { professores em um curso de formação } \\
\text { continuada para a utilização de objetos de } \\
\text { aprendizagem. }\end{array}$ & $\begin{array}{l}\text { Analisar os conhecimentos revelados por } \\
\text { professores de Matemática em um curso } \\
\text { de formação continuada ao utilizarem } \\
\text { OA nas aulas de Geometria. }\end{array}$ \\
\hline & $\begin{array}{l}\text { Veronica } \\
\text { Lopes } \\
\text { Pereira de } \\
\text { Oliveira }\end{array}$ & $\begin{array}{l}\text { Vivenciando objetos de aprendizagem na } \\
\text { perspectiva da aprendizagem } \\
\text { significativa: análise das contribuições de } \\
\text { uma formação continuada desenvolvida } \\
\text { com um grupo de Professores de } \\
\text { Matemática de Ipatinga (MG). }\end{array}$ & $\begin{array}{l}\text { Analisar as contribuições da utilização de } \\
\text { OA em um curso de formação } \\
\text { professores de Matemática focado na } \\
\text { aprendizagem significativa. }\end{array}$ \\
\hline \multirow{4}{*}{2014} & $\begin{array}{c}\text { Gisele } \\
\text { Barbosa }\end{array}$ & $\begin{array}{l}\text { Objetos de aprendizagem como recurso } \\
\text { educacional digital para Educação } \\
\text { Financeira Escolar: análise e avaliação. }\end{array}$ & $\begin{array}{l}\text { Analisar os aspectos pedagógicos e } \\
\text { técnicos da utilização de um OA como } \\
\text { recurso educacional para o ensino de } \\
\text { educação financeira escolar. }\end{array}$ \\
\hline & $\begin{array}{c}\text { Wagner } \\
\text { Cesar } \\
\text { Bernandes }\end{array}$ & $\begin{array}{l}\text { Objetos digitais de aprendizagem e o } \\
\text { desenvolvimento de habilidades } \\
\text { espaciais: um estudo de caso no } 6^{\circ} \text { ano do } \\
\text { Ensino Fundamental. }\end{array}$ & $\begin{array}{l}\text { Verificar como os OA auxiliam o aluno a } \\
\text { desenvolver habilidades espaciais. }\end{array}$ \\
\hline & $\begin{array}{l}\text { Anagela } \\
\text { Cristina } \\
\text { Morete }\end{array}$ & $\begin{array}{l}\text { Estudo dos registros de representação } \\
\text { semiótica mediados por um objeto de } \\
\text { aprendizagem. }\end{array}$ & $\begin{array}{l}\text { Investigar possíveis contribuições da } \\
\text { utilização de um OA para o estudo das } \\
\text { representações semióticas. }\end{array}$ \\
\hline & $\begin{array}{l}\text { Daniela } \\
\text { Alves da } \\
\text { Silveira } \\
\text { Moura. }\end{array}$ & $\begin{array}{l}\text { Perspectivas no estudo de limite: numa } \\
\text { perspectiva figural e conceitual - foco em } \\
\text { objetos de aprendizagem. }\end{array}$ & $\begin{array}{l}\text { Compreender as manifestações de } \\
\text { representação e os processos de ensino e } \\
\text { aprendizagem no estudo de Cálculo, } \\
\text { sobretudo nos tópicos de Limite e } \\
\text { Continuidade. }\end{array}$ \\
\hline \multirow{3}{*}{2015} & $\begin{array}{l}\text { Alcione } \\
\text { Cappelin }\end{array}$ & $\begin{array}{l}\text { O ensino de funções na lousa digital a } \\
\text { partir do uso de um objeto de } \\
\text { aprendizagem construído com vídeos. }\end{array}$ & $\begin{array}{l}\text { Analisar uma proposta metodológica de } \\
\text { ensino, vinculada à construção e } \\
\text { aplicação de um OA na lousa digital, com } \\
\text { base na teoria cognitiva de aprendizagem } \\
\text { multimídia. }\end{array}$ \\
\hline & $\begin{array}{c}\text { Bruna } \\
\text { Derossi }\end{array}$ & $\begin{array}{l}\text { Objetos de aprendizagem e lousa digital } \\
\text { no trabalho com Álgebra: as estratégias } \\
\text { dos alunos na utilização desses recursos. }\end{array}$ & $\begin{array}{l}\text { Identificar as estratégias utilizados por } \\
\text { alunos do } 9^{\circ} \text { Ano do Ensino Fundamental } \\
\text { II, na resolução de problemas de Álgebra } \\
\text { com o uso de OA nas lousas digitais. }\end{array}$ \\
\hline & $\begin{array}{c}\text { Jose } \\
\text { Eustaquio } \\
\text { Pinto } \\
\end{array}$ & $\begin{array}{l}\text { Objeto de aprendizagem para o ensino de } \\
\text { números complexos com aplicações na } \\
\text { área Técnica em Eletroeletrônica. }\end{array}$ & $\begin{array}{l}\text { Construir um OA para o ensino de } \\
\text { Número Complexos com aplicações na }\end{array}$ \\
\hline
\end{tabular}




\begin{tabular}{|c|c|c|c|}
\hline & & & $\begin{array}{l}\text { Educação Profissional Técnica de Nível } \\
\text { Médio em Eletroeletrônica. }\end{array}$ \\
\hline \multirow{6}{*}{2016} & $\begin{array}{l}\text { Geancarlo } \\
\text { Almeida } \\
\text { Antunes }\end{array}$ & $\begin{array}{l}\text { Objeto de aprendizagem para funções } \\
\text { exponencial e logarítmica com } \\
\text { aplicações no Ensino Médio e em Cursos } \\
\text { Técnicos. }\end{array}$ & $\begin{array}{l}\text { Construir um OA para o ensino de } \\
\text { Funções Exponenciais com aplicações na } \\
\text { Educação Profissional Técnica de Nível } \\
\text { Médio em Mecânica. }\end{array}$ \\
\hline & $\begin{array}{l}\text { Naysa } \\
\text { Taboada } \\
\text { Silva } \\
\text { Alvarenga }\end{array}$ & $\begin{array}{l}\text { Objetos de aprendizagem na Educação } \\
\text { Estatística: recursos didáticos no } 1^{\circ} \text { ano } \\
\text { do Ensino Fundamental. }\end{array}$ & $\begin{array}{l}\text { Analisar as propostas de práticas } \\
\text { pedagógicas de objetos de aprendizagem } \\
\text { relacionados à Educação Estatística no } 1^{\circ} \\
\text { ano do Ensino Fundamental. }\end{array}$ \\
\hline & $\begin{array}{l}\text { Renata } \\
\text { Oliveira } \\
\text { Balbino }\end{array}$ & $\begin{array}{l}\text { Os objetos de aprendizagem de } \\
\text { Matemática do PNLD 2014: uma análise } \\
\text { segundo as visões construtivista e } \\
\text { ergonômica. }\end{array}$ & $\begin{array}{l}\text { Analisar os OA aprovados pelo PNLD } \\
2014 \text {, para os anos finais do Ensino } \\
\text { Fundamental de Matemática, segundo } \\
\text { critérios de análise e seleção de sites } \\
\text { educacionais sob o paradigma } \\
\text { construtivista e ergonômico. }\end{array}$ \\
\hline & $\begin{array}{l}\text { Josino } \\
\text { Lucindo } \\
\text { Mendes } \\
\text { Junior }\end{array}$ & $\begin{array}{l}\text { Objeto de aprendizagem hiperligado com } \\
\text { materiais manipuláveis para o ensino de } \\
\text { Geometria Espacial para alunos com } \\
\text { baixa visão na educação básica. }\end{array}$ & $\begin{array}{l}\text { Desenvolver um OA que possibilite o } \\
\text { ensino e aprendizagem de Geometria } \\
\text { Espacial para alunos com baixa visão. }\end{array}$ \\
\hline & $\begin{array}{l}\text { Fabio } \\
\text { Henrique } \\
\text { Patriarca }\end{array}$ & $\begin{array}{l}\text { Contribuições do Programa M@ @tmídias } \\
\text { para a integração de tecnologia às aulas } \\
\text { de trigonometria no Ensino Médio. }\end{array}$ & $\begin{array}{l}\text { Identificar tanto as possibilidades de } \\
\text { integração de tecnologia ao ensino de } \\
\text { trigonometria quanto às de construção de } \\
\text { conhecimento profissional dos } \\
\text { participantes. }\end{array}$ \\
\hline & $\begin{array}{l}\text { Cassiano } \\
\text { Scott Puhl }\end{array}$ & $\begin{array}{l}\text { Números complexos: interação e } \\
\text { aprendizagem. }\end{array}$ & $\begin{array}{l}\text { Desenvolver um OA para ser } \\
\text { potencialmente significativo, com uma } \\
\text { rota de aprendizagem, para compreensão } \\
\text { de número complexos. }\end{array}$ \\
\hline \multirow{3}{*}{2017} & $\begin{array}{l}\text { Aloisio } \\
\text { Moises } \\
\text { Dauanny } \\
\text { Junior }\end{array}$ & $\begin{array}{l}\text { Objeto de aprendizagem para o estudo do } \\
\text { conceito de função e seu comportamento } \\
\text { com modelos matemáticos no Ensino } \\
\text { Médio e na Educação Profissional } \\
\text { Técnica. }\end{array}$ & $\begin{array}{l}\text { Pesquisar o conceito de função com o uso } \\
\text { de um OA em dois grupos de pesquisa de } \\
\text { Minas Gerais. }\end{array}$ \\
\hline & $\begin{array}{l}\text { Airan } \\
\text { Priscila de } \\
\text { Farias }\end{array}$ & $\begin{array}{l}\text { O software de programação Scratch na } \\
\text { formação inicial do professor de } \\
\text { Matemática por meio da criação de } \\
\text { objetos de aprendizagem. }\end{array}$ & $\begin{array}{l}\text { Desenvolver OA, no formato de jogo } \\
\text { digital, para o ensino de Geometria em } \\
\text { um curso de formação inicial de } \\
\text { professores. }\end{array}$ \\
\hline & $\begin{array}{l}\text { Luciano } \\
\text { Alves } \\
\text { Leão }\end{array}$ & $\begin{array}{l}\text { Contribuições do uso de um objeto de } \\
\text { aprendizagem na aprendizagem } \\
\text { significativa dos conceitos de } \\
\text { representação por partes, equivalência e } \\
\text { comparação de números racionais na } \\
\text { forma fracionária. }\end{array}$ & $\begin{array}{l}\text { Verificar as contribuições do OA, } \\
\text { "Frações Do Professor Sagaz" na } \\
\text { aprendizagem de conceitos relativos aos } \\
\text { números racionais na representação } \\
\text { fracionária, em uma perspectiva de } \\
\text { aprendizagem significativa. }\end{array}$ \\
\hline
\end{tabular}




\begin{tabular}{|c|c|c|c|}
\hline & $\begin{array}{c}\text { Tatiana } \\
\text { Fernandes } \\
\text { Meireles }\end{array}$ & $\begin{array}{l}\text { Desenvolvimento de um objeto de } \\
\text { aprendizagem de Matemática usando o } \\
\text { Scratch: da elaboração à construção. }\end{array}$ & $\begin{array}{l}\text { Investigar quais são as possíveis etapas } \\
\text { de elaboração de um OA utilizando o } \\
\text { software de programação Scratch. }\end{array}$ \\
\hline & $\begin{array}{l}\text { Cinthia } \\
\text { Domit } \\
\text { Zaniolo } \\
\text { Renaux }\end{array}$ & $\begin{array}{l}\text { O uso de objetos de aprendizagem de } \\
\text { estatística em um curso de Pedagogia: } \\
\text { algumas possibilidades } \\
\text { potencialidades. }\end{array}$ & $\begin{array}{l}\text { Analisar como a utilização de OA de } \\
\text { Matemática na disciplina de Estatística } \\
\text { no Curso de Pedagogia pode contribuir } \\
\text { para a formação de futuros professores. }\end{array}$ \\
\hline & $\begin{array}{l}\text { Fábio } \\
\text { Roberto } \\
\text { Vicentini }\end{array}$ & $\begin{array}{l}\text { A lousa digital e a aprendizagem do } \\
\text { professor que ensina matemática. }\end{array}$ & $\begin{array}{l}\text { Identificar que evidências de } \\
\text { aprendizagem científica/tecnológica, } \\
\text { docente e da pesquisa podem ser } \\
\text { percebidas quando um professor } \\
\text { pesquisador faz uso da lousa digital e está } \\
\text { envolvido em entendê-la e utilizá-la no } \\
\text { ensino e na aprendizagem de matemática. }\end{array}$ \\
\hline & $\begin{array}{l}\text { Beatriz } \\
\text { Maria } \\
\text { Zoppo }\end{array}$ & $\begin{array}{l}\text { A Contribuição do Scratch como } \\
\text { possibilidade de material didático digital } \\
\text { de Matemática no Ensino Fundamental I. }\end{array}$ & $\begin{array}{l}\text { Investigar como os estudantes de uma } \\
\text { turma do } 5 .^{\circ} \text { ano do Ensino Fundamental } \\
\text { de uma escola da Rede Municipal de } \\
\text { Ensino de Curitiba interagem frente ao } \\
\text { uso de um OA sobre o conteúdo unidades } \\
\text { de medida de comprimento, construído } \\
\text { com o uso do software Scratch. }\end{array}$ \\
\hline 2018 & $\begin{array}{l}\text { Taniele } \\
\text { Loss Nesi }\end{array}$ & 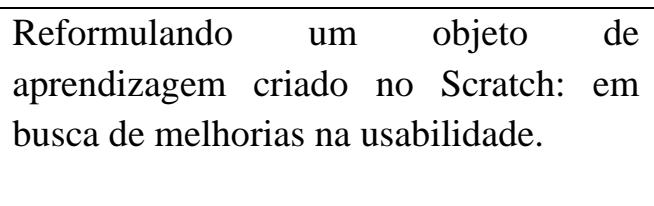 & $\begin{array}{l}\text { Reformular um OA matemático } \\
\text { desenvolvido no software Scratch a fim } \\
\text { de aperfeiçoar seus aspectos de } \\
\text { usabilidade. }\end{array}$ \\
\hline 2019 & $\begin{array}{l}\text { Maria Das } \\
\text { Merces } \\
\text { Coutinho } \\
\text { Mota }\end{array}$ & $\begin{array}{l}\text { O uso de objetos de aprendizagem para o } \\
\text { ensino e aprendizagem de Estatística no } \\
\text { Ensino Médio. }\end{array}$ & $\begin{array}{l}\text { Promover, por meio do uso de OA, o } \\
\text { desenvolvimento da habilidade } 27, \\
\text { presente na competência } 07 \text { da Matriz } \\
\text { Curricular de Matemática do Exame } \\
\text { Nacional do Ensino Médio (ENEM). }\end{array}$ \\
\hline
\end{tabular}

Na Figura 3 apresentamos uma nuvem de palavras com os principais termos disponibilizados no objetivo geral dos estudos. As palavras maiores representam os termos mais recorrentes, tais como, OA, ensino e aprendizagem. Outras palavras que aparecem em destaque são: uso, professor, aluno, curso, lousa, formação, dentre outras. Os verbos com maior incidência são: analisar, identificar, utilizar e desenvolver, demonstrando que a maior parte das dissertações focam na formação, aplicação ou construção de um OA. A identificação dessas palavras possibilita a delimitação dos subfocos e focos temáticos essenciais no processo de categorização. 
Figura 3.

Nuvem de palavras com os principais termos dos objetivos gerais (Fonte: Autoria Própria, 2020).

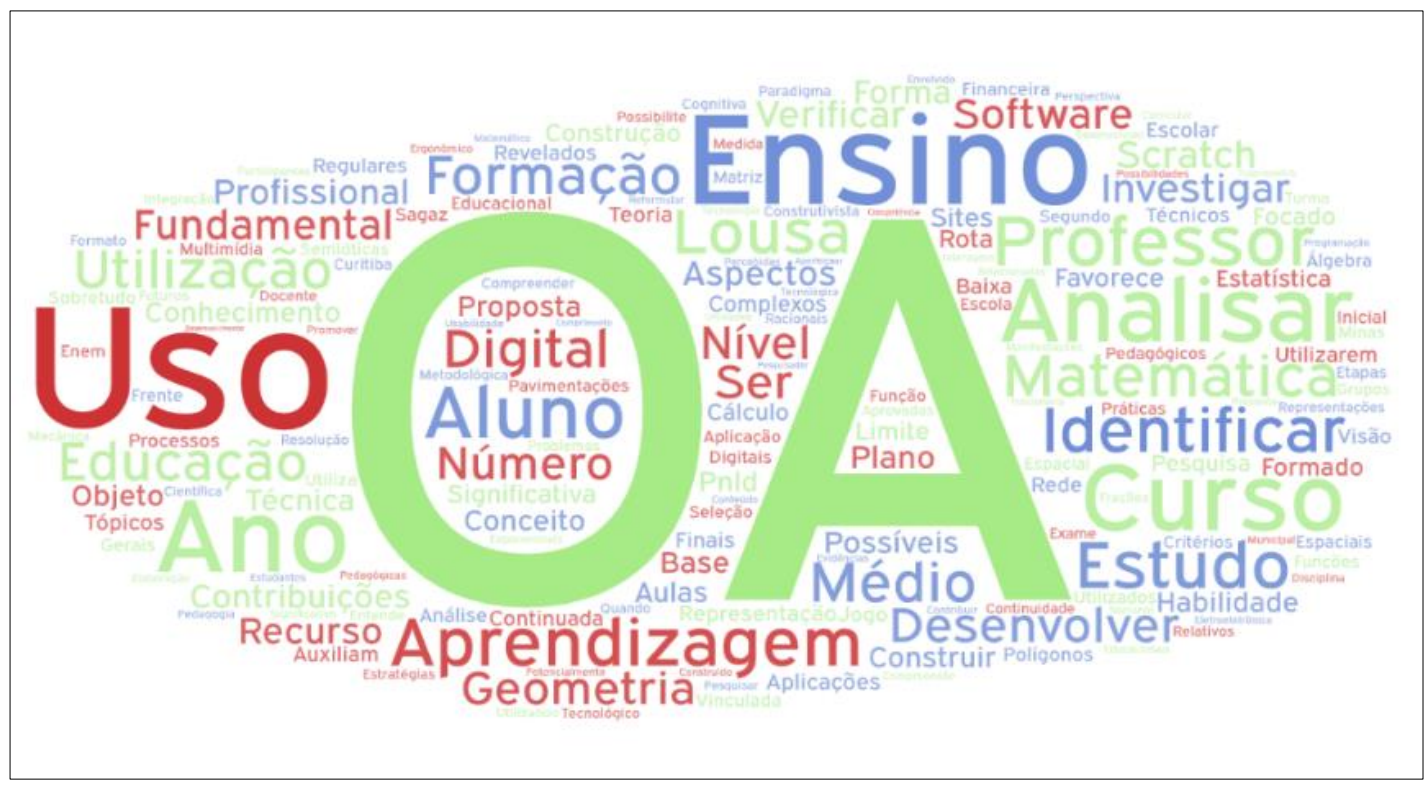

A categorização ocorre de maneira indutiva, em alguns casos dedutiva, possibilitando que as categorias surjam do próprio estudo em análise (Fiorentini, 2002). Para Motta, Kalinke \& Mocrosky $(2018$, p. 70) o processo de categorização permite “ [...] uma estruturação sistemática das informações, favorecendo o agrupamento das mensagens de acordo com suas semelhanças". Ainda segundo Fiorentini (2002) o processo de categorização permite a obtenção de um

[...] quadro dos estudos organizados tematicamente, é uma elaboração particular relativa àquele conjunto de trabalhos, não sendo, portanto, facilmente transferível para outros conjuntos. A vantagem dessa forma de organização é que ela permite comparar por contraste os diferentes olhares e resultados produzidos, independendo da opção teórica ou metodológica de cada estudo. Isso não significa ecletismo. Significa, acima e tudo, respeito à diversidade e às múltiplas formas de produzir conhecimentos dentro de um campo específico como o da Educação Matemática (Fiorentini, 2002, p. 5).

Para o estabelecimento das categorias faz-se necessário a desconstrução do texto, de forma a organizá-lo buscando atender ao objetivo geral estabelecido pela pesquisa. Cabe destacar que um estudo pode pertencer a mais de um subfoco ou foco temático, pois, essa percepção depende da forma como os pesquisadores entendem os trabalhos. A Tabela 2 
apresenta a categorização das 25 dissertações, organizadas em subfocos e focos temático de acordo com a percepção dos autores deste artigo.

Tabela 2.

Organização das pesquisas em subfocos e focos temático.

\begin{tabular}{|c|c|c|c|c|c|}
\hline $\begin{array}{c}\text { Subfoco } \\
\text { Temático }\end{array}$ & $\begin{array}{c}\mathbf{N} \\
\mathbf{o}\end{array}$ & Autor & Foco Temático & $\mathbf{N}^{\mathbf{o}}$ & Autor \\
\hline \multirow{3}{*}{ Lousa Digital } & \multirow{3}{*}{3} & Cappelin (2015) & \multirow{6}{*}{$\begin{array}{c}\text { Aplicação de } \\
\text { um OA }\end{array}$} & \multirow{6}{*}{6} & Correa (2013) \\
\hline & & Vicentini (2017) & & & Bernardes (2014) \\
\hline & & Derossi (2015) & & & Moura (2014) \\
\hline \multirow{4}{*}{ Geometria } & \multirow{4}{*}{4} & Correa (2013) & & & Derossi (2015) \\
\hline & & Mendes Júnior (2016) & & & Leão (2017) \\
\hline & & Farias (2017) & & & Zoppo (2017) \\
\hline & & Bernardes (2014) & \multirow{7}{*}{$\begin{array}{l}\text { Formação de } \\
\text { Professores por } \\
\text { meio do uso de } \\
\text { um OA }\end{array}$} & \multirow{7}{*}{7} & Nifoci (2013) \\
\hline \multirow{4}{*}{$\begin{array}{c}\text { Formação de } \\
\text { Professores }\end{array}$} & \multirow{4}{*}{4} & Nifoci (2013) & & & Oliveira (2013) \\
\hline & & Oliveira (2013) & & & Morete (2014) \\
\hline & & Balbino (2016) & & & Alvarenga (2016) \\
\hline & & Morete (2014) & & & Patriarca (2016) \\
\hline \multirow{3}{*}{$\begin{array}{c}\text { Números } \\
\text { Complexos e } \\
\text { Trigonometria }\end{array}$} & \multirow{3}{*}{3} & Pinto (2015) & & & Renaux (2017) \\
\hline & & Puhl (2016) & & & Vincentin (2017) \\
\hline & & Patriarca (2016) & \multirow{12}{*}{$\begin{array}{l}\text { Avaliação, } \\
\text { Construção ou } \\
\text { Reformulação } \\
\text { de um OA }\end{array}$} & \multirow{12}{*}{12} & Barbosa (2014) \\
\hline \multirow{3}{*}{ Função } & \multirow{3}{*}{3} & Antunes (2016) & & & Pinto (2015) \\
\hline & & $\begin{array}{c}\text { Dauanny Junior } \\
\text { (2017) }\end{array}$ & & & Capellin (2015) \\
\hline & & Moura (2014) & & & Balbino (2016) \\
\hline \multirow{4}{*}{$\begin{array}{l}\text { Educação } \\
\text { Estatística e } \\
\text { Financeira }\end{array}$} & \multirow{4}{*}{4} & Alvarega (2016) & & & $\begin{array}{l}\text { Mendes Júnior } \\
(2016)\end{array}$ \\
\hline & & Mota (2019) & & & Puhl (2016) \\
\hline & & Renaux (2017) & & & Antunes (2016) \\
\hline & & Barbosa (2014) & & & Meireles (2017) \\
\hline \multirow{4}{*}{$\begin{array}{l}\text { Números } \\
\text { Racionais e } \\
\text { Unidades de } \\
\text { Medidas }\end{array}$} & \multirow{4}{*}{4} & Leão (2017) & & & Farias (2017) \\
\hline & & Zoppo (2017) & & & $\begin{array}{c}\text { Dauanny Junior } \\
\text { (2017) }\end{array}$ \\
\hline & & Meireles (2017) & & & Nesi (2018) \\
\hline & & Nesi (2018) & & & Mota (2019) \\
\hline
\end{tabular}

\section{Apresentação dos dados da revisão sistemática de literatura}

Esta fase consiste na apresentação dos estudos, inicialmente, por meio da realização do tratamento dos dados, destacando as principais informações e características dos trabalhos. Evidenciamos que a maior parte das pesquisas se concentram no ano de 2016 (24\%) e 2017 (28\%). No período compreendido entre 2013 e 2015 foram realizados 10 estudos, perfazendo 
40\% das dissertações identificadas, e nos anos de 2018 e 2019 foram retornados apenas dois estudos, ou seja, cerca de $8 \%$ dos trabalhos catalogados.

Tabela 3.

Origem dos trabalhos mapeados.

\begin{tabular}{|c|c|c|c|c|c|}
\hline $\mathbf{N}^{\mathbf{o}}$ & Dissertação & Instituição & $\begin{array}{c}\text { Tipo de } \\
\text { instituição }\end{array}$ & Programa & $\begin{array}{c}\text { Tipo de } \\
\text { Programa }\end{array}$ \\
\hline 1 & Correa (2013) & UFSC & Pública & $\begin{array}{lll}\begin{array}{l}\text { Educação } \\
\text { Tecnológica }\end{array} & \text { Cientifica } & \text { e } \\
\end{array}$ & MA \\
\hline 2 & Nifoci (2013) & PUCSP & Privada & Educação Matemática & MA \\
\hline 3 & Oliveira (2013) & UFOP & Pública & Educação Matemática & MP \\
\hline 4 & Barbosa (2014) & UFJF & Pública & Ensino de Matemática & MP \\
\hline 5 & Bernardes (2014) & UFRGS & Pública & Ensino de Matemática & MP \\
\hline 6 & Morete (2014) & UEL & Pública & $\begin{array}{l}\text { Ensino de Ciências e Educação } \\
\text { Matemática }\end{array}$ & MA \\
\hline 7 & Moura (2014) & PUCMG & Privada & Ensino & MP \\
\hline 8 & Cappelin (2015) & UFPR & Pública & $\begin{array}{l}\text { Educação em Ciências e em } \\
\text { Matemática }\end{array}$ & MA \\
\hline 9 & Derossi (2015) & UFPR & Pública & $\begin{array}{l}\text { Educação em Ciências e em } \\
\text { Matemática }\end{array}$ & MA \\
\hline 10 & Pinto (2015) & PUCMG & Privada & Ensino & MP \\
\hline 11 & Antunes (2016) & PUCMG & Privada & Ensino & MP \\
\hline 12 & Alvarenga (2016) & IFES & Pública & $\begin{array}{l}\text { Educação em Ciências e } \\
\text { Matemática }\end{array}$ & MP \\
\hline 13 & Balbino (2016) & UFPR & Pública & $\begin{array}{l}\text { Educação em Ciências e em } \\
\text { Matemática }\end{array}$ & MA \\
\hline 14 & $\begin{array}{l}\text { Mendes Junior } \\
(2016)\end{array}$ & UFG & Pública & $\begin{array}{l}\text { Mestrado Profissional em } \\
\text { Ensino na Educação Básica }\end{array}$ & MP \\
\hline 15 & Patriarca (2016) & UNIDERP & Privada & Educação Matemática & MA \\
\hline 16 & Puhl (2016) & UCS & Privada & $\begin{array}{l}\text { Ensino de Ciências e } \\
\text { Matemática }\end{array}$ & MP \\
\hline 17 & $\begin{array}{l}\text { Dauanny Junior } \\
\text { (2017) }\end{array}$ & PUCMG & Privada & Ensino & MP \\
\hline 18 & Farias (2017) & UTFPR & Pública & Ensino de Matemática & MP \\
\hline 19 & Leão (2017) & UNCSUL & Privada & $\begin{array}{l}\text { Ensino de Ciências e } \\
\text { Matemática }\end{array}$ & MP \\
\hline 20 & Meireles (2017) & UFPR & Pública & $\begin{array}{l}\text { Educação em Ciências e em } \\
\text { Matemática }\end{array}$ & MA \\
\hline 21 & Renaux (2017) & UFPR & Pública & $\begin{array}{l}\text { Educação em Ciências e em } \\
\text { Matemática }\end{array}$ & MA \\
\hline 22 & Vincentin (2017) & UEL & Pública & $\begin{array}{l}\text { Ensino de Ciências e Educação } \\
\text { Matemática }\end{array}$ & MA \\
\hline 23 & Zoppo (2017) & UFPR & Pública & $\begin{array}{l}\text { Educação em Ciências e em } \\
\text { Matemática }\end{array}$ & MA \\
\hline 24 & Nesi (2018) & UTFPR & Pública & $\begin{array}{ll}\text { Formação } & \text { Científica, } \\
\text { Educacional e Tecnológica }\end{array}$ & MP \\
\hline 25 & Mota (2019) & UFJF & Pública & Educação Matemática & MP \\
\hline
\end{tabular}

Legenda: MA: Mestrado Acadêmico; MP: Mestrado Profissional; UFSC: Universidade Federal de Santa Catarina; UFPR: Universidade Federal do Paraná; UFJF: Universidade Federal de Juiz de Fora; UTFPR:

Universidade Tecnológica Federal do Paraná; PUCSP: Pontifícia Universidade Católica de São Paulo; 
PUCMG: Pontifícia Universidade Católica de Minas Gerais; UEL: Universidade Estadual de Londrina; UNICUSL: Universidade Cruzeiro do Sul; UNIDERP: Universidade Anhanguera; UCS: Universidade de Caxias do Sul; UFG: Universidade Federal de Goiás; IFES: Instituto Federal do Espírito Santo; UFGRS: Universidade Federal do Rio Grande do Sul; UFOP: Universidade Federal de Ouro Preto.

Com relação à origem dos trabalhos, conforme destacado na Tabela 3, evidenciamos que $68 \%$ foram realizadas em instituições públicas e $32 \%$ na rede privada de Ensino Superior. Observamos, ainda, que 96\% das pesquisas estão centralizadas nas Regiões Sul e Sudeste, não sendo encontrados estudos nas Regiões Norte e Nordeste. Na Região Sul a instituição com o maior número de trabalhos é a UFPR, com seis pesquisas, e na Região Sudeste a PUCMG, com quatro pesquisas.

Em relação ao tipo de programa, nota-se que $56 \%$ das pesquisas estão vinculadas a cursos de mestrado profissional, ou seja, buscam "contribuir com uma prática docente efetiva que proporcione uma ressignificação dos processos de ensino e aprendizagem" (Motta, Kalinke \& Mocrosky, 2018, p. 66) e desenvolvem produtos educacionais que possibilitam a aplicação prática de um OA em sala de aula. Em contrapartida, os trabalhos realizados em programas de mestrado acadêmico evidenciam questões teóricas ou práticas sobre o uso de um OA, buscando entender como esses recursos colaboram com os processos de ensino e aprendizagem na Matemática.

Sobre os autores, $80 \%$ possuem Licenciatura em Matemática e o restante é formado em Pedagogia. Cerca de $40 \%$ atuam como professores de escolas públicas, lecionando a disciplina de Matemática ou Física; 28\% lecionam matemática na rede privada de ensino; 20\% atuam como pedagogos de escolas públicas; $8 \%$ não apresentam informações profissionais; e 4\% atuam em órgãos da administração executiva.

Dentre os vários instrumentos metodológicos utilizados nas pesquisas, destacam-se: análise documental, observações, entrevistas, diário de bordo; anotações, análises narrativas, análise de OA, construção de OA, gravações, questionários, entre outros. Na Tabela 4, apresentamos estes instrumentos e as pesquisas que os utilizaram. 
Tabela 4.

Principais instrumentos metodológicos presentes nas dissertações.

\begin{tabular}{|c|l|}
\hline Instrumentos Metodológicos & \multicolumn{1}{c|}{ Dissertações } \\
\hline Registro de atividades & $\begin{array}{l}\text { Correa (2013), Moura (2014), Derossi (2015), Leão (2017) } \\
\text { e Mota (2019). }\end{array}$ \\
\hline Análises narrativas & Nifoci (2013). \\
\hline Gravações & Oliveira (2013). \\
\hline Observações Participantes & $\begin{array}{l}\text { Oliveira (2013), Alvarenga (2016), Patriarca (2016), Zoppo } \\
\text { (2017), Farias (2017) e Vincentin (2017) }\end{array}$ \\
\hline Registros escritos & Oliveira (2013), Morete (2014) e Bernardes (2014). \\
\hline Levantamento bibliográfico & Barbosa (2014) e Derossi (2015). \\
\hline Anotações & Bernardes (2014), Moura (2014) e Farias (2017) \\
\hline Etapas para construção de um OA & $\begin{array}{l}\text { Capellin (2015), Pinto (2015), Antunes (2016), Puhl } \\
\text { (2016), Zoppo (2017), Meireles (2017), Farias (2017) e } \\
\text { Nesi (2018). }\end{array}$ \\
\hline Etapas para análise de um OA & Balbino (2016) e Renaux (2017). \\
\hline Entrevistas & Alvarenga (2016) e Farias (2017). \\
\hline Questionários & Alvarenga (2016), Duanny Junior (2017) e Farias (2017). \\
\hline Interações durante um curso de \\
formação & Patriarca (2016). \\
\hline Rota de aprendizagem & Puhl (2016), Bernardes (2014). \\
\hline
\end{tabular}

Todas a pesquisas adotam uma abordagem qualitativa de natureza descritiva e interpretativa. O público-alvo dos estudos eram estudantes das séries finais do Ensino Fundamental, professores em formação inicial ou continuada ou os próprios pesquisadores, durante o processo de elaboração, construção ou reformulação de um OA. Apenas o trabalho de Mendes Junior (2016) não apresenta informações sobre seus aspectos metodológicos, pois, a pesquisa não possui divulgação autorizada e essas informações não estão evidenciadas no seu resumo, disponibilizado pela Capes.

\section{Os objetos de aprendizagem nas pesquisas}

Neste tópico apresentamos os estudos, buscando caracterizar as pesquisas identificadas no portifólio bibliográfico obtido. Inicialmente, cabe destacar que alguns autores consideram os OA conforme apontado pela Learning Objects Metadata Workgroup (LOM), como sendo entidades que podem ser digitais ou não, desde que possam ser utilizados, reutilizados e referenciados na aprendizagem, com o uso de tecnologias (Nifoci, 2013; Bernardes, 2014; Antunes, 2016; Patriarca, 2016; Alvarenga, 2016; Vincentin, 2017; Dauanny Junior, 2017; 
Mota, 2019). A maior parte dos estudos não compartilham de uma mesma definição sobre o que são os OA, ou seja, não existe uma universalização de conceitos entre os autores que tratam deste artefato digital (Correa, 2013; Nifoci, 2013; Oliveira, 2013; Morete, 2014; Pinto, 2015; Balbino, 2016).

Em relação às definições adotadas sobre um OA, alguns estudos utilizam a concepção de Wiley (2000), já apresentada na introdução deste artigo, destacando a necessidade dos objetos serem reutilizáveis no suporte a aprendizagem (Oliveira, 2013; Barbosa, 2014; Moura, 2014; Pinto, 2015; Puhl, 2016; Dauanny Junior, 2017). Outras pesquisas apontam a perspectiva do GPTEM e GPINTEDUC como referência para sua análise (Capellin, 2015; Derossi, 2015; Farias, 2017; Meireles, 2017; Renaux, 2017; Nesi, 2018). Essas definições, diferenciam-se apenas ao que tange à sua aplicação, pois, para o GPTEM a utilização desses recursos deve ocorrer em um conteúdo específico, por meio de uma atividade interativa que esteja no formato de animação ou simulação, e para o GPINTEDUC eles podem ser aplicados em diferentes contextos educacionais e são classificados como softwares educacionais.

Todos os trabalhos ressaltam características técnicas e/ou pedagógicas dos OA. Em relação aos aspectos técnicos são destacadas: portabilidade: capacidade de ser utilizado em qualquer plataforma, sistema operacional e navegador; reusabilidade: capacidade de ser reutilizável em diferentes contextos, sem a necessidade de ser remodelado e reestruturado; recuperabilidade: capacidade de apresentar informações essenciais para sua identificação, por meio de metadados; acessibilidade: capacidade de ser utilizado por pessoas com necessidades especiais; escalabilidade: capacidade de ser utilizado por qualquer número de pessoas; granularidade: capacidade de ser agrupado ou reagrupado em conjuntos maiores ou menores de conteúdos; indexação: capacidade de apresentar informações que permitam sua catalogação; usabilidade: capacidade de permitir uma facilidade de navegação; versatilidade: capacidade de armazenamento e organização dos elementos de sua construção de forma 
simples; e autocontido: capacidade de ser utilizado independente de se ter acesso, ou não, a internet (Nifoci, 2013; Oliveira, 2013; Barbosa, 2014; Bernardes, 2014; Morete, 2014; Capellin, 2015; Derossi, 2015; Pinto, 2015; Antunes, 2016; Balbino, 2016; Puhl, 2016; Dauanny Junior, 2017; Farias, 2017; Leão, 2017; Meireles, 2017; Renaux, 2017; Vincentin, 2017; Mota, 2019).

Sobre os aspectos pedagógicos dos $\mathrm{OA}$ os trabalhos apresentam: reusabilidade: capacidade de ser adaptado a um novo contexto pedagógico; interatividade: capacidade de o usuário agir sobre o objeto, recebendo "[...] em troca uma retroação da máquina sobre ele" (Belloni, 1999, p. 58); autonomia: capacidade do usuário em controlar sua interatividade sobre o objeto; cooperação: capacidade de proporcionar a colaboração entre usuários e a interação com o professor; ações cognitivas: capacidade de criar condições que propiciem a aprendizagem; autoconsciente: capacidade de ser autoexplicativo, permitindo que o usuário o utilize de forma autônoma; contextualizado: capacidade de apresentar informações do cotidiano dos usuários; modularidade: capacidade de ser utilizado de forma fragmentada e independente; organização: capacidade de apresentar o conteúdo de forma sequencial e organizada; sociabilidade: capacidade de ser cooperativo e promover a interdisciplinaridade; e tempo de aprendizagem: capacidade de determinar um tempo adequado para a realização das atividades propostas (Correa, 2013; Oliveira, 2013; Barbosa, 2014; Puhl, 2016; Farias, 2017; Leão, 2017; Meireles, 2017; Mota, 2019).

Outra característica que é destacada por Wiley (2000) diz respeito aos benefícios didáticos dos OA, que são: reutilização, revisão, remixagem e redistribuição, relacionando-os aos Recursos Educacionais Abertos (REA), o que o autor chamou de 4R, ampliando assim o significado de reutilização (Pinto, 2015; Antunes, 2016). Outra classificação identificada foi a organização dos OA de acordo com sua funcionalidade, podendo ser organizados em: instrução, colaboração, prática e avaliação (Mota, 2019). 
Além disso, destacam-se os conceitos de usabilidade e ergonomia, requisitos essenciais nos processos de avaliação de um OA. Na usabilidade os objetos são avaliados quanto à organização do ambiente, se apresentam instruções claras e objetivas, se as telas são agradáveis e atraente para os usuários, se a interatividade proposta possibilita a aprendizagem, se a linguagem oral e escrita é adequada, se há ausência de erros ortográficos e de programação. (Nifoci, 2013; Puhl, 2016; Nesi, 2018). Quanto a ergonomia, estão postulados três aspectos: legibilidade, documentação e navegabilidade (Balbino, 2017).

Muitos recursos podem ser considerados um OA, dos quais se destacam: imagens, vídeos, áudios, animações, simulações, hipertextos, aplicativos moveis, softwares, entre outros. Cabe destacar que as pesquisas que apontam essa diversidade de artefatos como sendo um OA adotam a definição de Wiley (2000) (Patriarca, 2016; Leão, 2017; Vincentin, 2017; Mota, 2019). Todas as pesquisas indicam que o local de armazenamento de um OA é denominado repositório. Os repositórios mais destacados foram: RIVED; Banco Internacional de Objetos de Aprendizagem; CESTA; UNIJUI; Laboratório Virtual da USP; MDMat; Portal e-Unicamp; Ariadne; Careo; Merlot; e Wisc-Online.

Com base nos focos temáticos estabelecidos na Tabela 1, podemos destacar o cerne das pesquisas. Observamos que maior parte, cerca de $40 \%$, constroem ou remixam um OA para ser aplicado em situações educacionais (Cappelin, 2015; Pinto, 2015; Antunes, 2016; Puhl, 2016; Mendes Junior, 2016; Dauanny Junior, 2017; Farias, 2017; Nesi, 2018; Meireles, 2018; Mota, 2019). Cerca de $8 \%$ buscam apresentar propostas de avaliação de OA para contextos educacionais (Barbosa, 2014; Balbino, 2016). Em 28\% dos estudos busca-se identificar contribuições do uso dos $\mathrm{OA}$ aos processos de ensino e aprendizagem, apresentando possibilidades de aplicação desses artefatos a conteúdos específicos durante a formação inicial ou continuada de professores (Nifoci, 2013; Oliveira, 2013; Morete, 2014; Alvarenga, 2016; Patriarca, 2016; Renaux, 2017; Vincentin, 2017) e 24\% dos trabalhos destacam a forma como 
ocorre a interatividade e o desenvolvimento dos processos cognitivos dos alunos na utilização de um OA (Correa, 2013; Bernandes, 2014; Moura, 2014; Derossi, 2015; Leão, 2017; Zoppo, 2017).

Algumas das pesquisas apresentam teorias para subsidiar a utilização dos OA em seu contexto. As principais teorias identificadas foram: Teoria da Representação Semiótica (Morete 2014; Moura, 2014), Inteligência Coletiva (Cappelin, 2015; Derossi, 2015; Balbino, 2016), Teoria da Aprendizagem Multimídia (Cappelin, 2015), Teoria da Atividade Modifica pela Tecnologia da Informação (Derossi, 2015; Balbino, 2016), Construcionismo (Farias, 2017; Nesi, 2018), Construtivismo (Balbino, 2016) e a Teoria da Aprendizagem Significativa (Oliveira, 2013; Puhl, 2016; Leão, 2017).

Os conteúdos matemáticos evidenciados nos OA foram: Geometria: com foco nas habilidades espaciais e na planificação (Correa, 2013; Bernardes, 2014; Mendes Junior, 2016; Farias, 2017); Álgebra: destacando os conceitos de funções, limite e continuidade (Moura, 2014; Derossi, 2015; Antunes, 2016; Dauanny Junior, 2017; Vincentin, 2017); Aritmética: evidenciando os conceitos de frações, números complexos, medidas e comprimentos (Pinto, 2015; Puhl, 2016; Leão, 2017; Meireles, 2017; Zoppo, 2017; Nesi, 2018); Estatística: com enfoque no desenvolvimento de competências e habilidades para uma melhor interpretação de dados cotidianos (Alvarenga, 2016; Renaux, 2017; Mota, 2019); Trigonometria: buscando evidenciar as contribuições visuais da utilização de uma TD no ensino desse conteúdo (Patriarca, 2016); e Educação Financeira: caracterizando as contribuições dessa temática na formação de um cidadão crítico e reflexivo na sociedade (Barbosa, 2014).

As pesquisas, que buscavam construir ou remixar um $\mathrm{AO}$, evidenciaram diversas ferramentas, que utilizam de uma programação visual mais acessível e intuitiva, possibilitando que professores e alunos possam desenvolver seus próprios artefatos digitais. Dentre as ferramentas mais citadas nos trabalhos tem-se o software de programação Scratch, que é 
recurso digital desenvolvido pela Massachusetts Institute of Technology (MIT), para a criação de ambientes interativos e imersivos que podem potencializar a aprendizagem, de forma a promover a interatividade e a colaboração (Farias, 2017; Meireles, 2017; Zoppo, 2017; Nesi, 2018). O GeoGebra, software de geometria dinâmica, interativa, livre e multiplataforma, criado em 2001 por Markus Hohernwarter, também é citado em alguns estudos no desenvolvimento de OA no formato de Applets $^{7}$ (Moura, 2014; Cappelin, 2015). Outro software associado as aplicações do GeoGebra foi o eXeLearning que é de código aberto e permite a publicação de conteúdos digitais para suporte a aprendizagem (Antunes, 2016).

Também são apontadas pesquisas que utilizam o software Hot Potatoes, desenvolvido no Canadá e executável utilizando um navegador web, para criação de exercícios participativos (palavras cruzadas, lacunas, combinação, sentenças e escolha múltipla) e publicado no formato de um OA (Cappelin, 2015; Vincentin, 2017; Mota, 2019). Outro ponto de destaque nos trabalhos é a associação dos OA à Lousa Digital, permitindo que o aluno acesse e manipule o conteúdo, possibilitando o seu desenvolvimento cognitivo (Cappelin, 2015; Derossi, 2015; Vincentin, 2017).

Em $48 \%$ dos trabalhos ocorreu a identificação ou nomeação de algum OA, dos quais se destacam: Pavimentação com polígonos regulares (Correa, 2013); ODA - Building freely, Copy the building, Rotation game, Building with three sides, Guess the view (Bernades, 2014); Balança Interativa (Morete, 2014); Funções Exponencial e Logarítmica com Aplicações no Ensino Médio e em Cursos Técnicos (Antunes, 2014); Balanza Algebraica (Derrosi, 2015); A dança do sol, a roda gigante e ondas trigonométricas (Patriarca, 2016); É o bicho, tabela de frações e porcentagens, brincando e aprendendo com gráficos e tabelas e animais domésticos e silvestres (Alvarenga, 2016; Renaux, 2017); Equation-grapher (Vincentin, 2017);

\footnotetext{
${ }^{7}$ Applet são aplicações executadas no contexto de outros softwares. Esses recursos visam proporcionar a interatividade por meio da interface de usuário ou aparecem no contexto de uma página da internet.
} 
Descobrindo comprimentos (Meireles, 2017; Zoppo, 2017); Frações do Professor Sagaz (Leão, 2017); e Aprendendo Medidas (Mota, 2019). Em 4\% das pesquisas não ocorreu a definição de um OA, ficando a cargo dos sujeitos envolvidos a escolha pelo recurso que atendesse as suas necessidades (Oliveira, 2013).

Conforme apontado na Tabela 3, 56\% dos estudos ocorram em programas de mestrado profissional e se torna relevante, para este artigo, destacar como estas pesquisas contribuem para a Educação Matemática. Cabe destacar que a definição de produto educacional para este artigo é qualquer material, oriundo de programas stricto sensu profissionais, produzido em formato digital ou não, que possa ser usado, reutilizado, remixado (com os devidos créditos a fonte original) e compartilhado, para utilização em contextos educacionais. Os produtos educacionais realizados podem ser textos, aplicativos, critérios avaliativos, sequências didáticas, livros, e-books, softwares, áudios, vídeos, OA, manuais, apostilas, sites, entre outros. Neste sentido, foram identificados os seguintes produtos educacionais: sequências didáticas (Bernardes, 2014; Antunes, 2016); cadernos de atividades (Moura, 2014); manual explicativo para avaliação ou criação de um OA (Barbosa, 2014; Farias, 2017); site (Alvarenga, 2016); construção de um OA (Pinto, 2015; Mendes Junior, 2016; Puhl, 2016; Dauanny Junior, 2017; Nesi, 2018; Mota, 2019).

\section{Considerações finais}

Utilizar as TD em sala de aula requer que o professor modifique suas formas de conceber como a Matemática é desenvolvida na sala de aula. Neste sentido, é essencial que os processos de ensino e aprendizagem ocorram de forma que a inserção de artefatos tecnológicos, tornem o ambiente escolar um espaço ativo, lúdico e colaborativo, no qual a interatividade ocorre sempre na utilização de qualquer recurso digital. Para Motta \& Kalinke (2019, p. 216), é neste contexto que se inserem os OA, pois, eles possibilitam que o professor tenha “[...] uma atuação efetiva como mediador dos processos educacionais, possibilitando a ele escolher ou 
desenvolver o seu próprio artefato tecnológico, de forma que este se torne um recurso significativo para os estudantes".

Neste artigo, buscou-se apresentar, por meio de um RSL, o que tem sido investigado por pesquisadores brasileiros sobre o uso de OA na Educação Matemática, tendo como questão norteadora "Quais as pesquisas no Catálogo de Teses e Dissertações da Capes que discorrem sobre objetos de aprendizagem na Educação Matemática?". A busca retornou 75 trabalhos, que após a aplicação dos critérios de exclusão e inclusão, resultou em 25 dissertações, sendo a maior parte dessas, cerca de $48 \%$, concentradas na avaliação, construção ou remodelação de OA.

Todos os estudos catalogados mostram-se relevantes na identificação das possíveis contribuições dos OA aos processos de ensino e aprendizagem de conteúdos matemáticos. Dado este contexto, entende-se que a inserção de tais artefatos pode "[...] modificar os ambientes culturais e educativos, criando modos de comunicação e interação em sala de aula" (Motta, Kalinke \& Mocrosky, 2018, p. 219).

Uma constatação nas pesquisas foi a indicação da não uniformização sobre o conceito de OA. Notamos que alguns autores utilizam as definições de Wiley (2000), de outros pesquisadores, ou usam definições associadas à grupos de pesquisas. Nota-se ainda a ampla concentração dos trabalhos nas Regiões Sul (52\%) e Sudeste (44\%) e que a maior parte das pesquisas foram realizadas em programas de mestrado profissional (56\%). Além disso, evidencia-se uma divergência, entre os autores, sobre quais artefatos podem ser considerados um OA. Alguns apontam a necessidade da interatividade e outros apenas a intenção do objeto durante a sua aplicação. Nos OA usados, reutilizados ou remixados nas pesquisas, percebe-se uma concentração em atividades voltadas para o aprimoramento de conceitos algébricos ou aritméticos. Além disso, os trabalhos que tinham como escopo a construção de um OA 
utilizaram softwares de fácil manipulação ou com uma programação visual e intuitiva, tais como, Scratch, Hot Potatoes e GeoGebra.

Algumas lacunas foram evidenciadas, tais como, a realização de poucas pesquisas nas séries iniciais do Ensino Fundamental e no Ensino Superior, a não identificação de pesquisas de doutorado, a necessidade de uma metodologia específica para avaliar e construir um OA, uma definição mais precisa do que se entende sobre reusabilidade e a realização de cursos formativos.

Evidenciou-se, na apresentação dos dados, que o percentual das pesquisas que versam sobre a utilização de OA na Educação Matemática (cerca de 2,8\%), ainda é baixo, se comparado a outras temáticas relacionadas ao uso de tecnologias digitais. Considera-se que a temática é pouco explorada, pois, exige dos pesquisadores alguns conhecimentos em softwares de design (Hot Potatoes, JClic etc.) ou ferramentas de programação intuitiva (Scratch, App Inventor 2, etc.) e ainda a utilização de critérios de usabilidade e ergonomia.

De maneira geral, considera-se que a questão norteadora foi respondida, principalmente, ao se compreender a visão dos pesquisadores sobre o uso dos OA nas atividades didáticas e pedagógicas de Matemática. Por fim, cabe salientar que a organização dos dados proposta neste artigo não é rígida, pois, infere-se que uma alteração nas fases de planejamento e condução da RSL, pode apresentar um outro portifólio bibliográfico.

\section{Referências}

Alvarenga, N. T. S. (2016). Objetos de aprendizagem na educação estatística: recursos didáticos no lo ano do ensino fundamental [Dissertação de Mestrado Profissional em Educação em Ciências e https://repositorio.ifes.edu.br/handle/123456789/126

Antunes, G. A. (2016) Objeto de aprendizagem para funções exponencial e logarítmica com aplicações no ensino médio e em cursos técnicos [Dissertação de Mestrado Profissional em Ensino]. http://pucmg.br/pos/ensino/index-padrao.php?pagina=5447

Balbino, R. O. (2016). Os objetos de aprendizagem de matemática do PNLD 2014: uma análise segundo as visões construtivista e ergonômica. [Dissertação de Mestrado em 
Educação em Ciências e em Matemática Instituição de Ensino]. https://acervodigital.ufpr.br/handle/1884/44080

Barbosa, G. (2014). Objetos de aprendizagem como recurso educacional digital para educação financeira escolar: análise e avaliação. [Dissertação de Mestrado Profissional em Educação http://www.ufjf.br/mestradoedumat/files/2011/05/Disserta\%C3\%A7\%C3\%A3oGisele-Barbosa.pdf

Belloni, M. L. Educação a distância. São Paulo: Autores Associados, 1999.

Bernardes, W. C. (2014). Objetos digitais de aprendizagem e o desenvolvimento de habilidades espaciais: um estudo de caso no $6^{\circ}$ ano do Ensino Fundamental. [Dissertação de Mestrado Profissional em Ensino de Matemática]. https://lume.ufrgs.br/handle/10183/115212

Borba, M. C., \& Vilarreal, M. E. (2005). Humans-with-Media and the Reorganization of Mathematical Thinking: Information and Communication Technologies, Modeling, Experimentation and Visualization. Bolema, 18 (24). http://www.periodicos.rc.biblioteca.unesp.br/index.php/bolema/article/view/10509/69 $\underline{18}$

Brasil. Ministério da Educação. Secretaria de Educação a Distância. (2007). Objetos de aprendizagem: uma proposta de recurso pedagógico. Organização: Carmem Lúcia Prata, Anna Christina Aun de Azevedo Nascimento. Brasília: MEC, SEED.

Campos, C. J. G. (2004). Método de Análise de Conteúdo: ferramenta para análise de dados qualitativos no campo da saúde. Revista Brasileira de Enfermagem, Brasília.

Cappelin, A. (2015). O ensino de funções na lousa digital a partir do uso de um objeto de aprendizagem construído com vídeos [Dissertação de Mestrado em Educação em Ciências e em Matemática Instituição de Ensino]. http://hdl.handle.net/1884/41864

Correa, N. (2013). Estudo das pavimentações do plano utilizando um objeto de aprendizagem [Dissertação de Mestrado em Educação Cientifica e Tecnológica]. https://repositorio.ufsc.br/handle/123456789/106892

Dauanny Junior, A. M. (2017). Objeto de aprendizagem para o estudo do conceito de função e seu comportamento com modelos matemáticos no ensino médio e na educação profissional técnica [Dissertação de Mestrado Profissional em Ensino]. http://www.biblioteca.pucminas.br/teses/EnCiMat_Dauanny\%20JuniorAM_1.pdf

Derossi, B. (2015). Objetos de aprendizagem e lousa digital no trabalho com álgebra: as estratégias dos alunos na utilização desses recursos. 2015 [Dissertação de Mestrado em Educação em Ciências e em Matemática Instituição de Ensino]. http://hdl.handle.net/1884/38192

Elias, A. P., Motta, M. S.; \& Kalinke, M. A. (2018). Construção de Objetos de Aprendizagem para a Educação Básica por Meio de um Curso Sobre o Scratch para Estudantes de Licenciaturas. Revista Renote, Porto Alegre, 16 (1), p. 1-12.

Farias, A. P. (2017). O software de programação scratch na formação inicial do professor de matemática por meio da criação de objetos de aprendizagem [Dissertação de Mestrado Profissional em Ensino de Matemática]. http://repositorio.utfpr.edu.br/jspui/bitstream/1/3039/1/LD_PPGMAT_M_Curci\%2C \%20Airan\%20Priscila\%20de\%20Farias_2017.pdf 
Fiorentini, D. (2002). Mapeamento e balanço dos trabalhos do GT-19 (Educação Matemática) no período de 1998 a 2001. Anais da 25a Reunião Anual da ANPEd (pp. 1-17). Caxambu: Associação Nacional de Pós-Graduação. http://25reuniao.anped.org.br/encomendados/mapeamentobalancogt19.doc .

Fiorentini, D. et al. (2016). O professor que ensina matemática como campo de estudo: concepção do projeto de pesquisa. In: FIORENTINI, D.; PASSOS, C. L. B.; LIMA, R. C. R. (Org). Mapeamento da pesquisa acadêmica brasileira sobre o professor que ensina matemática: período 2001-2012. São Paulo: FE/UNICAMP, p.17- 41.

Galvão, T. F., \& Pereira, M.G. (2014). Revisões sistemáticas da literatura: passos para sua elaboração. Revista Epidemiol. Serv. Saúde, Brasília, v. 23, n. 1, p. 183-184.

Gpinteduc. (2020). Grupo de Pesquisa em Inovação e Tecnologias na Educação. https://gpinteduc.wixsite.com/utfpr

Gptem. (2020). Grupo de Pesquisa sobre Tecnologias na Educação Matemática. https://gptem5.wixsite.com/gptem

Gutierres, S. S. (2004). Distribuição de conteúdos e aprendizagem on-line. Renote, v. 2, p. 1 14.

Kalinke, M. A.; \& Motta, M.S. (2019). À guisa de apresentações, definições e contextualizações. In: Kaline, M. A.; Motta, M. S. (Orgs). Objetos de Aprendizagem: pesquisas e possibilidades na educação matemática. Campo Grande: Life Editora, p.721.

Kenski, V. M. (2007). Educação e tecnologias: o novo ritmo da informação. Campinas, SP: Papirus.

Leão, L. A. (2017). Contribuições do uso de um objeto de aprendizagem na aprendizagem significativa dos conceitos de representação por partes, equivalência e comparação de números racionais na forma fracionária [Dissertação de Mestrado Profissional em Ensino de Ciências e Matemática].

Lévy, P. (1993). As Tecnologias da Inteligência: o futuro do pensamento na era da informática. São Paulo: 34.

Meireles, T. F. (2017). Desenvolvimento de um objeto de aprendizagem de matemática usando o scratch: da elaboração à construção [Dissertação de Mestrado em Educação em Ciências e em Matemática Instituição de Ensino]. https://hdl.handle.net/1884/56109

Mendes Junior, J. L. (2016). Objeto de aprendizagem hiperligado com materiais manipuláveis para o ensino de geometria espacial para alunos com baixa visão na educação básica [Dissertação de Mestrado Profissional em Ensino na Educação Básica]. http://repositorio.bc.ufg.br/tede/handle/tede/5999

Mendes, R. M., Souza, V. I., \& Caregnato, S. I. (2007). A Propriedade Intelectual na Elaboração de Objetos de Aprendizagem. https://www.lume.ufrgs.br/bitstream/handle/10183/548/000502901.pdf? sequence=1

Morete, A. C. (2014). Estudo dos registros de representação semiótica mediados por um objeto de aprendizagem [Dissertação de Mestrado em Ensino de Ciências e Educação Matemática]. http://www.uel.br/pos/mecem/arquivos_pdf/Dissertacao-ANAGELApdf.pdf

Mota, M. M. C. (2019). O uso de objetos de aprendizagem para o ensino e aprendizagem de Estatística no Ensino Médio [Dissertação de Mestrado Profissional em Educação 
Matemática]. http://www.ufjf.br/mestradoedumat/files/2011/05/DISSERTACAO_MARIA_DAS MERCES.pdf

Motta, M. S, Kalinke, M. A., \& CURCI, A. F. (2019). Um produto educacional para orientar a criação de objetos de aprendizagem matemática no software de programação Scratch. Revista de Educação, Ciências e Matemática, Campinas, 9 (1), p. 238-251.

Motta, M. S., \& Kalinke, M. A. (2019). Uma proposta metodológica para a produção de objetos de aprendizagem na perspectiva educacional. In: Kalinke, M. A., \& Motta, M. S. (Orgs). Objetos de Aprendizagem: pesquisas e possibilidades na educação matemática. Campo Grande: Life Editora, p. 203-218.

Motta, M. S., Basso, S. T. L., \& Kalinke, M. A. (2019). Mapeamento sistemático das pesquisas realizadas nos programas de mestrado profissional que versam sobre a aprendizagem matemática na educação infantil. Revista ACTIO: Docência em Ciências, Curitiba, 4 (3), p. 204-225.

Motta, M. S., Kalinke, M. A., \& Mocrosky, L. F. (2018). Mapeamento das dissertações que versam sobre o uso de tecnologias educacionais no ensino de Física. Revista ACTIO: Docência em Ciências, Curitiba, 3 (3), p. 65-85.

Moura, D. A. S. (2014). Perspectivas no estudo de limite: numa perspectiva figural e conceitual - foco em objetos de aprendizagem [Dissertação de Mestrado Profissional em Ensino].

Nesi, T. L. (2018). Reformulando um objeto de aprendizagem criado no scratch: em busca de melhorias na usabilidade [Dissertação (Mestrado Profissional em Formação Científica, Educacional e Tecnológica]. https://bityli.com/dsU4E

Nifoci, R. E. M. (2013). Conhecimentos revelados por professores em um curso de formação continuada para a utilização de objetos de aprendizagem [Dissertação de Mestrado em Educação Matemática]. https://tede2.pucsp.br/handle/handle/10970

Oliveira, V. L. P. (2013). Vivenciando objetos de aprendizagem na perspectiva da aprendizagem significativa: análise das contribuições de uma formação continuada desenvolvida com um grupo de professores de matemática de Ipatinga (MG) [Dissertação de Mestrado Profissional em Educação Matemática] https://www.repositorio.ufop.br/handle/123456789/3147

Patriarca, F. H. (2016). Contribuições do programa M@tmídias para a integração de tecnologia às aulas de trigonometria no ensino médio [Dissertação (Mestrado em Educação Matemática]. https://repositorio.pgsskroton.com/handle/123456789/21800

Pinto, J. E, Laudares, J. B. (2016). Objeto de Aprendizagem de Números Complexos com aplicações na área técnica em eletroeletrônica. Revista Brasileira de Ensino de Ciência e Tecnologia, Ponta Grossa, 9 (3), p. 103-118.

Pinto, J. E. (2015). Objeto de aprendizagem para o ensino de números complexos com aplicações na área técnica em eletroeletrônica [Dissertação de Mestrado Profissional em Ensino]. http://pucmg.br/pos/ensino/index-padrao.php?pagina=5307

Puhl, C. S. (2016). Números complexos: interação e aprendizagem [Dissertação (Mestrado Profissional em Ensino de Ciências e Matemática]. https://repositorio.ucs.br/xmlui/handle/11338/1144

Renaux, C. D. Z. (2017). O uso de objetos de aprendizagem de estatística em um curso de pedagogia: algumas possibilidades e potencialidades [Dissertação de Mestrado em 
Educação em Ciências e em Matemática Instituição de Ensino]. https://bityli.com/Tjqvq

Sampaio, R. F., \& Macini, M. C. Estudos de revisão sistemática: um guia para síntese criteriosa de evidências científicas. Revista Brasileira de Fisioterapia, São Carlos, 11 (1), p. 8389.

Schmitt, V. P.; Corbellini, S. O. (2014). Jogo Digital: a matemática na $4^{\mathrm{a}}$ série do ensino fundamental. In: TAROUCO, L. M. R. et al. (Orgs.). Objetos de Aprendizagem: teoria e prática. Porto Alegre, Evangraf, p. 331-347.

Tavares, R. (2010) Aprendizagem significativa, codificação dual e objetos de aprendizagem. http://www.fisica.ufpb.br/ romero/port/trabalhos.htm

Tavares, R. et al. (2008). Eletromagnetismo: Objetos de aprendizagem e a construção de significados baseados em um ambiente de múltiplas representações. http://www.fisica.ufpb.br/ romero/pdf/2008SBIERomeroNOA.pdf

Tikhomirov, O. K. (1981). The psychological Consequences of Computarization. In Wertsch, J. V. (Ed.). The Concept of Activity in Soviet Psychology. New York: M. E. Sharpe Inc. p. 256- 278 .

Vicentin, F. R. (2017). A lousa digital e a aprendizagem do professor que ensina matemática [Dissertação de Mestrado em Ensino de Ciências e Educação Matemática]. http://www.uel.br/pos/mecem/arquivos_pdf/FABIO\%20ROBERTO\%20VICENTIN.p $\underline{\mathrm{df}}$

Wiley, D. A. (2000). Connecting learning objects to instructional design theory:a definition, a metaphor, and a taxonomy. http://wesrac.usc.edu/wired/bldg7_file/wiley.pdf

Zoppo, B. M. (2017). A contribuição do scratch como possibilidade de material didático digital de matemática no ensino fundamental. [Dissertação de Mestrado em Educação em Ciências e em Matemática Instituição de Ensino]. https://hdl.handle.net/1884/53394

Recebido em: 17/06/2019

Aprovado em: 23/10/2020 